\title{
Costs to Australian taxpayers of pharmaceutical monopolies and proposals to extend them in the Trans-Pacific Partnership Agreement
}

\section{US ambitions \\ for the}

Trans-Pacific

Partnership

Agreement

... would

expand and

entrench costly

monopolies

in Australia,

with no

evidence of any

countervailing

benefit

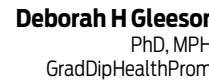

Hazel Moi

PhD, EMA, BA(Hons)

Ruth Lopert BMed, MMedSci, FAFPHM ${ }^{3}$

1 La Trobe University, Melbourne, VIC

2 Australian Nationa University,

Canberra, ACT.

3 George Washingto University

Washington, DC, USA

d.gleeson@

latrobe.edu.au

doi: 10.5694/mjal4.01682

Online first 23/02/15 ntellectual property (IP) provisions being pursued by the United States in the 12-country Trans-Pacific Partnership Agreement (TPPA) negotiations have generated widespread alarm since the initial US proposals were leaked in 2011..$^{1-5}$ Subsequent leaks of composite drafts of the IP chapter have shown ongoing resistance by most countries to many of the US proposals that would delay access to generic medicines. ${ }^{6,7}$ But while the most recently leaked draft suggests some modifications in the US position, ${ }^{7}$ major concerns related to medicines access remain unresolved.

This article focuses on three particular problems for Australia that remain in the $2014 \mathrm{draft}$. These are provisions that would further entrench secondary patenting and evergreening, lock in extensions to patent terms, and extend data protection for certain medicines. If agreed by negotiating countries, these provisions would futureproof existing low standards that are antithetical to promoting access to, and affordability of, medicines. These will not only extend monopolies over expensive new treatments, but will also make subsequent reform efforts increasingly difficult.

For each of the problems identified, we examined existing public domain data, drawn primarily from the 2013 Pharmaceutical Patents Review (PPR) and submissions to it, to identify the costs to Australian taxpayers of existing patent and data protection provisions, as well as those likely to accrue to taxpayers if the Australian Government accedes to US ambitions on these matters.

\section{Secondary patents and evergreening}

The pharmaceutical industry uses a practice known as evergreening to extend monopoly periods for medicines. Secondary patents are patents of very low inventiveness based on an original inventive patent for a new molecule. Evergreening patents are secondary patents held by the owner of the original patent. Evergreening presents a particular problem in countries with low patentability standards, such as Australia and the US.8,9

US researchers examined patents granted for two HIV drugs (ritonavir and lopinavir/ritonavir) and found that Abbott owned 82 secondary patents and had a further 26 pending applications in the US, all of which involved small variations on the original patents for these drugs. ${ }^{9}$ They found that these evergreening patents could delay generic competition for 19 years beyond the date from which generic entry would have been anticipated. ${ }^{9}$ This problem is largely due to low standards for patent grant,

\section{Summary}

- Intellectual property (IP) protections proposed by the United States for the Trans-Pacific Partnership Agreement (TPPA) have sparked widespread alarm about the potential negative impact on access to affordable medicines.

- The most recently leaked draft of the IP chapter shows some shifts in the US position, presumably in response to ongoing resistance from other countries. While some problematic provisions identified in earlier drafts have been removed or mitigated, major concerns remain unresolved.

- Three of the greatest concerns for Australia in the recent draft include provisions that would further entrench secondary patenting and evergreening, lock in extensions to patent terms and extend monopoly rights over clinical trial data for certain medicines.

- Data from the 2013 Pharmaceutical Patents Review, and from various submissions made to it, show that pharmaceutical monopoly protections already cost Australian taxpayers hundreds of millions of dollars each year.

- Provisions still being considered for the TPPA would further entrench and extend costly monopolies, with serious implications for the budget bottom line and the sustainability of the Pharmaceutical Benefits Scheme.

together with barriers to the challenge and revocation of questionable patents.

A study in Australia found an average of 49 secondary patents for each of the 15 highest-cost drugs over a 20-year period. ${ }^{10}$ One-quarter of these secondary patents were evergreening patents.

Evergreening delays generic market entry and imposes large unnecessary costs on the health care system - and on consumers. When a patent on a medicine expires and the first generic version is listed on the Pharmaceutical Benefits Scheme (PBS), a statutory reduction of $16 \%$ is applied to the PBS price and it is moved from the F1 to the F2 formulary. There, it becomes subject to the application of price disclosure, ${ }^{11}$ which further lowers prices over time.

Generic medicines manufacturer Alphapharm (a subsidiary of US-based Mylan) stated in its public submission to the PPR that:

In the case of Plavix (clopidogrel) the cost to the PBS of a near 3-year delay in the generic market entry caused by the grant of an interim injunction over an 
evergreening patent that was subsequently revoked has been estimated to be about $\$ 60$ million. However, the total cost to the PBS attributable to the revoked patent has been estimated to be about $\$ 644$ million (p. 6). ${ }^{12}$

The Australian Generic Medicines Industry Association analysed the costs to the health system for 39 PBS-listed medicines for which generic competition was delayed after the patent on the active pharmaceutical ingredient expired, as a result of secondary patenting. ${ }^{13}$ In the 12 months to November 2012, the cost of delayed generic launch was calculated at $\$ 37.8-\$ 48.4$ million. This estimate does not include subsequent price reductions due to price disclosure.

An illustration of how this affects consumers comes from the patents associated with an antidepressant, venlafaxine (Efexor). Two additional patents support the extendedrelease form, Efexor-XR. One of these was so broad that it delayed generic entry by two and a half years. By the time this patent was eventually declared invalid, the delay to generic market entry had cost Australian taxpayers $\$ 209$ million. ${ }^{14}$

Pfizer also successfully patented desvenlafaxine (marketed as Pristiq), the active metabolite of venlafaxine. Not only was a patent granted for desvenlafaxine, it was also given a term extension until August 2023. There is no evidence that Pristiq offers any clinical benefit over venlafaxine. ${ }^{15,16}$ But the cost to taxpayers of doctors prescribing Pristiq in preference to off-patent Efexor-XR has been estimated at more than $\$ 21$ million per year. ${ }^{14}$

The problem of evergreening in Australia is likely to be entrenched further by the provisions of the TPPA. A footnote to draft TPPA article QQE1 sets the current very low inventiveness approach in stone, making it difficult, if not impossible, to prevent further evergreening. ${ }^{17}$ Australia is supporting a provision that commits countries to make patents available for "any new uses, or alternatively, new methods of using a known product" (Art. QQE1.4(a)), ${ }^{7}$ as this is current Australian practice. But acceding to this provision in the treaty text will limit Australia's options for much needed patent reform in future.

\section{Patent term extension}

Australia is obliged to provide 20-year patents under the World Trade Organization's Agreement on TRIPS (Trade-Related Aspects of Intellectual Property Rights). In 1998, patent term extension provisions were introduced, allowing up to 5 years for delays in processing patent applications or in the regulatory approval process. These provisions were later locked in by the obligations of the Australia-US Free Trade Agreement (AUSFTA). ${ }^{3}$

The PPR found that about $58 \%$ of new molecules listed on the PBS from 2003 to 2010 received extensions of term. Of the term extensions granted since 1999, 47\% received the full 5 years. ${ }^{18}$ The cost of these extensions to the PBS in 2012-13 was estimated at about \$240 million in the medium term and about $\$ 480$ million in the longer term. ${ }^{18}$

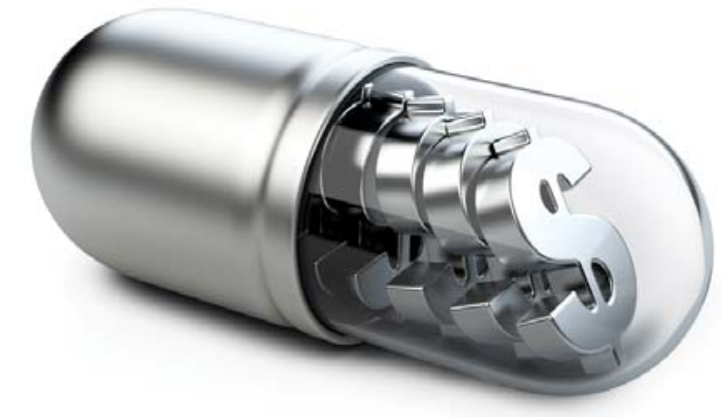

The PPR found that, contrary to claims by the pharmaceutical industry, there was no evidence that the public investment in extensions of term had led to a commensurate increase in investment in research and development. ${ }^{18}$ The PPR concluded that patent term extension was not in Australia's interests, and recommended reducing the maximum length of extensions or the maximum effective patent life.

The most recent draft TPPA IP text includes provisions for term extensions for delays in the processing of patents and in the regulatory approval process. ${ }^{7}$ While the leaked text indicates opposition by Australia to the former, and the latter is consistent with the AUSFTA, patent term extension has been widely reported as an area where the US has little support from other countries. Moreover, the Therapeutic Goods Administration (TGA) regulatory approval process for medicines is subject to a statutory time limit of 255 working days, after which the TGA forfeits $25 \%$ of the evaluation fee (Therapeutic Goods Regulations 1990 [ss. 16C; 43AA]). Thus, the routine granting of extensions to compensate for rare delays in the marketing approval process makes little sense.

Earlier leaked TPPA negotiating documents show that the US was seeking to mandate patent term extensions not just for new molecules, but also for new uses and new methods of using existing products. ${ }^{6}$ This extension of scope for term extensions seems to have been dropped from the $2014 \mathrm{draft},{ }^{7}$ a likely result of opposition by other countries. No evidence presented to the PPR indicated that extending the scope of patent term extensions would be in the national interest. ${ }^{18}$

\section{Data protection}

Data protection refers to preventing or delaying the reliance, by a generic manufacturer, on clinical trial data produced by the originator to support marketing approval of its product. Under the Commonwealth Therapeutic Goods Act 1989 (s. 25A), the TGA may not consider an application for a generic medicine where that application relies on undisclosed evidence of safety and efficacy submitted in support of the originator product for 5 years from the date of first registration. Data protection confers a monopoly that is distinct from that provided by the patent system, and is effective even where a patent has not been granted, or has expired. Unlike a patent, data protection cannot be subject to legal challenge. 
We are not aware of any analyses of the financial impact of data protection on the Australian health system, but studies in other countries have shown that its introduction leads to increased costs. Oxfam International found that data protection introduced in Jordan in 2001, together with other TRIPS Plus measures, delayed generic entry for $79 \%$ of medicines launched between 2002 and $2006 .{ }^{19}$ A later, more comprehensive study found that between 1999 and 2004 there was a 17\% increase in total medicines expenditure in Jordan, equating to additional costs of US\$18 million in $2004 . .^{20}$ The study concluded that data protection had the most significant effect on this price increase.

In addition to its effects on medicines expenditure, data protection also presents a potential barrier to compulsory licensing - a TRIPS-compliant strategy that countries may use to bypass patents where this is necessary for public health purposes. ${ }^{21}$

Proposals for the TPPA include 5 years of data protection for new products, an additional 3 years for data produced to support new uses of existing products, and a longer period of data protection for biologics (possibly up to 12 years). ${ }^{7}$ Biologics are produced through biotechnology processes involving living organisms; these include many new cancer, anti-rheumatic and multiple sclerosis medicines.

In the 2014 TPPA draft, data protection is limited to undisclosed data and data required by regulatory agencies, representing a narrowing of the scope in comparison with earlier drafts. ${ }^{7}$ However, extending data protection to new uses of existing products and allowing longer periods of protection for biologics are likely to lead to significant delays in the market entry of cheaper generics and biosimilars in Australia. Additional periods of 3 years of data protection for new indications were previously rejected by Australia in the AUSFTA negotiations. ${ }^{3}$

The PPR found that "data protection appears to have little impact on the levels of pharmaceutical investment in a country"..$^{18}$ It concluded that there was no evidence to indicate that current data protection provided insufficient incentives to innovate and bring biologic products to market, and recommended against extending data protection for biologics. In the US, the Federal Trade Commission also concluded that lengthy data protection for biologics was not warranted. ${ }^{22}$

A useful example of the costs of delaying market entry of competitors for biologics is adalimumab (Humira), a drug for rheumatoid arthritis and other autoimmune conditions. This drug represented the third-highest cost to government in 2013-14, costing Australian taxpayers $\$ 272.7$ million..$^{23}$ When the first biosimilar version is listed on the PBS, it will trigger a $16 \%$ statutory price reduction on all versions of the product. This means savings to taxpayers of $\$ 43.6$ million in the first year (based on 2013-14 expenditure data), and with flow-on effects resulting from price disclosure likely to lead to further savings in subsequent years.

\section{Conclusions}

Pharmaceutical monopoly protections already cost the Australian health system hundreds of millions of dollars each year. US ambitions for the TPPA IP chapter in the most recently leaked draft would expand and entrench costly monopolies in Australia, with no evidence of any countervailing benefit to the Australian public.

The PPR warned that the current Australian patent system was not well designed to serve Australia's interests. The government's stated concern about the need to ensure the sustainability of the PBS can hardly be credible if it ignores this warning in the final stages of the TPPA negotiations.

Competing interests: Deborah Gleeson receives funding from the Australian Research Council for research on the TPPA, health and nutrition. She has received funding from various national and international non-government organisations to attend speaking engagements related to trade agreements and health, including the TPPA. She has represented the Public Health Association of Australia on matters related to the TPPA. The views expressed in this article are ours and not those of any organisation we are affiliated with.

Provenance: Not commissioned; externally peer reviewed.

References are available online at www.mja.com.au. 
1 Gleeson DH, Tienhaara KS, Faunce TA. Challenges to Australia's national health policy from trade and investment agreements. Med J Aust 2012; 196: 354-356.

2 Lopert R, Gleeson D. The high price of "free" trade: US trade agreements and access to medicines. J Law Med Ethics 2013; 41: 199-223.

3 Faunce TA, Townsend R. The Trans-Pacific Partnership Agreement: challenges for Australian health and medicine policies. Med J Aust 2011; 194: 83-86.

4 UNITAID. The Trans-Pacific Partnership Agreement: implications for access to medicines and public health. Geneva: UNITAID Secretariat, World Health Organization, 2014. http://www.unitaid.eu/images/marketdynamics/ publications/TPPA-Report_Final.pdf (accessed Jan 2015).

5 Médecins Sans Frontières. Trading away health: the TransPacific Partnership Agreement. Briefing note. Geneva: MSF, 2014. http://www.msfaccess.org/sites/default/files/TPP_ IssueBriefing_July2014.pdf (accessed Nov 2014).

6 Wikileaks. Secret Trans-Pacific Partnership (TPP) - IP chapter. Leaked draft, intellectual property (rights) chapter, dated August 2013. https://wikileaks.org/tpp (accessed Nov 2014).

7 Wikileaks. Updated secret Trans-Pacific Partnership Agreement (TPP) - IP chapter (second publication). Leaked draft, intellectual property (rights) chapter, dated May 2014. https://wikileaks.org/tpp-ip2 (accessed Nov 2014)

8 Moir HVJ. Fabricating invention: the patent malfunction of Australian patent law. Agenda 2013; 20: 21-38. http://press.anu.edu.au/apps/bookworm/view/ Volume+20,+Number+2,+2013/10931/moir.xhtml (accessed Jan 2015).

9 Amin T, Kesselheim AS. Secondary patenting of branded pharmaceuticals: a case study of how patents on two HIV drugs could be extended for decades. Health Aff (Millwood) 2012; 31: 2286-2294.

10 Christie AF, Dent C, McIntyre P, et al. Patents associated with high-cost drugs in Australia. PLOS One 2013; 8: e60812.

1 Department of Health. Pharmaceutical Benefits Scheme price disclosure arrangements: procedural and operational guidelines. Canberra: DoH, 2014. http://www.pbs.gov.au/ industry/pricing/price-disclosure-spd/price-disclosureoperational-guidelines-july-2014.pdf;jsessionid=zaj335et4jq3 1506z9614j5s3 (accessed Jan 2015).

12 Alphapharm. Pharmaceutical patents review: relevant matters for public hearing Tuesday, 12 February 2013. http://web.archive.org/web/20130426003800/http:/ pharmapatentsreview.govspace.gov.au/files/2013/02/201302-12-Alphapharm-Submission-PUBLIC.pdf (accessed Jan 2015).
13 Generic Medicines Industry Association. Public response to the 2013 Pharmaceutical Patents Review. Sydney: GMiA, 2013: 11.

14 Moir HVJ, Gleeson D. Explainer: evergreening and how big pharma keeps drug prices high. The Conversation 2014; 6 Nov. https://theconversation.com/explainer-evergreening-andhow-big-pharma-keeps-drug-prices-high-33623 (accessed Nov 2014).

15 Your questions to the PBAC: patent expiry and "new drug" approvals. Aust Prescr 2009; 32: 63. http://www. australianprescriber.com/magazine/32/3/artid/1023 (accessed Jan 2015).

16 Pharmaceutical Benefits Advisory Committee. Desvenlafaxine succinate, tablet, (extended release), 50 mg and $100 \mathrm{mg}$ (base), Pristiq $®$, November 2008. Public summary document. http://www.pbs.gov.au/info/industry/ listing/elements/pbac-meetings/psd/2008-11/pbac-psddesvenlafaxine-nov08 (accessed Nov 2014).

17 Moir HVJ. Trade treaties and patent policy: searching for a balanced approach. Paper presented at 15th International Schumpeter Society Conference; 2014 Jul 2730; Jena, Germany. https://digitalcollections.anu.edu.au/ handle/1885/12493 (accessed Feb 2015).

18 Harris T, Nicol D, Gruen N. Pharmaceutical Patents Review report. Canberra: Commonwealth of Australia, 2013: 160. http://www.ipaustralia.gov.au/pdfs/2013:-05-27_PPR_Final_ Report.pdf (accessed Nov 2014).

19 Oxfam International. All costs, no benefits: how TRIPS-plus intellectual property rules in the US-Jordan FTA affect access to medicines. Briefing paper. 2007. http://www.oxfam. org/sites/www.oxfam.org/files/all\%20costs,\%20no\%20 benefits.pdf (accessed Nov 2014).

20 Abbott RB, Bader R, Bajjali L, et al. The price of medicines in Jordan: the cost of trade-based intellectual property. Journal of Generic Medicines 2012; 9: 75-85. doi: 10.1177/1741134312447499.

21 Sell SK. TRIPS-Plus free trade agreements and access to medicines. Liverp Law Rev 2007; 28: 41-75. doi: 10.1007/s10991007-9011-8.

22 United States Federal Trade Commission. Emerging health care issues: follow-on biologic drug competition. 2009. http://www.ftc.gov/reports/emerging-health-careissues-follow-biologic-drug-competition-federal-tradecommission-report (accessed Nov 2014).

23 PBS Information Management Section, Pharmaceutical Policy Branch. Expenditure and prescriptions twelve months to 30 June 2014. Canberra: Australian Government Department of Health, 2014. http://www.pbs.gov.au/ statistics/2013-2014-files/expenditure-and-prescriptions-12months-to-30-june-2014.pdf (accessed Jan 2015). 